Advances in Intelligent Systems and Computing 826

Sebastiano Bagnara Riccardo Tartaglia · Sara Albolino Thomas Alexander · Yushi Fujita Editors

Proceedings of the 20th Congress of the International Ergonomics Association (IEA 2018)

Volume IX: Aging, Gender and Work, Anthropometry, Ergonomics for Children and Educational Environments

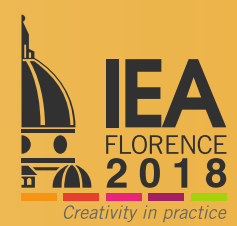




\section{Advances in Intelligent Systems and Computing}

Volume 826

Series editor

Janusz Kacprzyk, Polish Academy of Sciences, Warsaw, Poland

e-mail: kacprzyk@ibspan.waw.pl 
The series "Advances in Intelligent Systems and Computing" contains publications on theory, applications, and design methods of Intelligent Systems and Intelligent Computing. Virtually all disciplines such as engineering, natural sciences, computer and information science, ICT, economics, business, e-commerce, environment, healthcare, life science are covered. The list of topics spans all the areas of modern intelligent systems and computing such as: computational intelligence, soft computing including neural networks, fuzzy systems, evolutionary computing and the fusion of these paradigms, social intelligence, ambient intelligence, computational neuroscience, artificial life, virtual worlds and society, cognitive science and systems, Perception and Vision, DNA and immune based systems, self-organizing and adaptive systems, e-Learning and teaching, human-centered and human-centric computing, recommender systems, intelligent control, robotics and mechatronics including human-machine teaming, knowledge-based paradigms, learning paradigms, machine ethics, intelligent data analysis, knowledge management, intelligent agents, intelligent decision making and support, intelligent network security, trust management, interactive entertainment, Web intelligence and multimedia.

The publications within "Advances in Intelligent Systems and Computing" are primarily proceedings of important conferences, symposia and congresses. They cover significant recent developments in the field, both of a foundational and applicable character. An important characteristic feature of the series is the short publication time and world-wide distribution. This permits a rapid and broad dissemination of research results.

\section{Advisory Board}

\section{Chairman}

Nikhil R. Pal, Indian Statistical Institute, Kolkata, India

e-mail: nikhil@isical.ac.in

Members

Rafael Bello Perez, Universidad Central "Marta Abreu" de Las Villas, Santa Clara, Cuba

e-mail: rbellop@uclv.edu.cu

Emilio S. Corchado, University of Salamanca, Salamanca, Spain

e-mail: escorchado@usal.es

Hani Hagras, University of Essex, Colchester, UK

e-mail: hani@essex.ac.uk

László T. Kóczy, Széchenyi István University, Győr, Hungary

e-mail: koczy@sze.hu

Vladik Kreinovich, University of Texas at El Paso, El Paso, USA

e-mail:vladik@utep.edu

Chin-Teng Lin, National Chiao Tung University, Hsinchu, Taiwan

e-mail: ctlin@mail.nctu.edu.tw

Jie Lu, University of Technology, Sydney, Australia

e-mail: Jie.Lu@uts.edu.au

Patricia Melin, Tijuana Institute of Technology, Tijuana, Mexico

e-mail: epmelin@hafsamx.org

Nadia Nedjah, State University of Rio de Janeiro, Rio de Janeiro, Brazil

e-mail: nadia@eng.uerj.br

Ngoc Thanh Nguyen, Wroclaw University of Technology, Wroclaw, Poland

e-mail: Ngoc-Thanh.Nguyen@pwr.edu.pl

Jun Wang, The Chinese University of Hong Kong, Shatin, Hong Kong

e-mail: jwang @mae.cuhk.edu.hk

More information about this series at http://www.springer.com/series/11156 
Sebastiano Bagnara $\cdot$ Riccardo Tartaglia Sara Albolino · Thomas Alexander Yushi Fujita

Editors

Proceedings of the 20th Congress of the International Ergonomics Association (IEA 2018)

Volume IX: Aging, Gender and Work, Anthropometry, Ergonomics for Children and Educational Environments

Springer 


\section{Editors}

Sebastiano Bagnara

University of the Republic of San Marino

San Marino, San Marino

\section{Riccardo Tartaglia \\ Centre for Clinical Risk Management and Patient Safety, Tuscany Region Florence, Italy}

\author{
Sara Albolino \\ Centre for Clinical Risk Management \\ and Patient Safety, Tuscany Region \\ Florence, Italy
}

\author{
Thomas Alexander \\ Fraunhofer FKIE \\ Bonn, Nordrhein-Westfalen \\ Germany
}

\author{
Yushi Fujita \\ International Ergonomics Association \\ Tokyo, Japan
}

ISSN 2194-5357

ISSN 2194-5365 (electronic)

Advances in Intelligent Systems and Computing

ISBN 978-3-319-96064-7 ISBN 978-3-319-96065-4 (eBook)

https://doi.org/10.1007/978-3-319-96065-4

Library of Congress Control Number: 2018950646

\section{(C) Springer Nature Switzerland AG 2019}

This work is subject to copyright. All rights are reserved by the Publisher, whether the whole or part of the material is concerned, specifically the rights of translation, reprinting, reuse of illustrations, recitation, broadcasting, reproduction on microfilms or in any other physical way, and transmission or information storage and retrieval, electronic adaptation, computer software, or by similar or dissimilar methodology now known or hereafter developed.

The use of general descriptive names, registered names, trademarks, service marks, etc. in this publication does not imply, even in the absence of a specific statement, that such names are exempt from the relevant protective laws and regulations and therefore free for general use.

The publisher, the authors, and the editors are safe to assume that the advice and information in this book are believed to be true and accurate at the date of publication. Neither the publisher nor the authors or the editors give a warranty, express or implied, with respect to the material contained herein or for any errors or omissions that may have been made. The publisher remains neutral with regard to jurisdictional claims in published maps and institutional affiliations.

This Springer imprint is published by the registered company Springer Nature Switzerland AG The registered company address is: Gewerbestrasse 11, 6330 Cham, Switzerland 


\section{Preface}

The Triennial Congress of the International Ergonomics Association is where and when a large community of scientists and practitioners interested in the fields of ergonomics/human factors meet to exchange research results and good practices, discuss them, raise questions about the state and the future of the community, and about the context where the community lives: the planet. The ergonomics/human factors community is concerned not only about its own conditions and perspectives, but also with those of people at large and the place we all live, as Neville Moray (Tatcher et al. 2018) taught us in a memorable address at the IEA Congress in Toronto more than twenty years, in 1994.

The Proceedings of an IEA Congress describes, then, the actual state of the art of the field of ergonomics/human factors and its context every three years.

In Florence, where the XX IEA Congress is taking place, there have been more than sixteen hundred (1643) abstract proposals from eighty countries from all the five continents. The accepted proposal has been about one thousand (1010), roughly, half from Europe and half from the other continents, being Asia the most numerous, followed by South America, North America, Oceania, and Africa. This Proceedings is indeed a very detailed and complete state of the art of human factors/ergonomics research and practice in about every place in the world.

All the accepted contributions are collected in the Congress Proceedings, distributed in ten volumes along with the themes in which ergonomics/human factors field is traditionally articulated and IEA Technical Committees are named:

I. Healthcare Ergonomics (ISBN 978-3-319-96097-5).

II. Safety and Health and Slips, Trips and Falls (ISBN 978-3-319-96088-3).

III. Musculoskeletal Disorders (ISBN 978-3-319-96082-1).

IV. Organizational Design and Management (ODAM), Professional Affairs, Forensic (ISBN 978-3-319-96079-1).

V. Human Simulation and Virtual Environments, Work with Computing Systems (WWCS), Process control (ISBN 978-3-319-96076-0). 
VI. Transport Ergonomics and Human Factors (TEHF), Aerospace Human Factors and Ergonomics (ISBN 978-3-319-96073-9).

VII. Ergonomics in Design, Design for All, Activity Theories for Work Analysis and Design, Affective Design (ISBN 978-3-319-96070-8).

VIII. Ergonomics and Human Factors in Manufacturing, Agriculture, Building and Construction, Sustainable Development and Mining (ISBN 978-3-319-96067-8).

IX. Aging, Gender and Work, Anthropometry, Ergonomics for Children and Educational Environments (ISBN 978-3-319-96064-7).

X. Auditory and Vocal Ergonomics, Visual Ergonomics, Psychophysiology in Ergonomics, Ergonomics in Advanced Imaging (ISBN 978-3-31996058-6).

Altogether, the contributions make apparent the diversities in culture and in the socioeconomic conditions the authors belong to. The notion of well-being, which the reference value for ergonomics/human factors is not monolithic, instead varies along with the cultural and societal differences each contributor share. Diversity is a necessary condition for a fruitful discussion and exchange of experiences, not to say for creativity, which is the "theme" of the congress.

In an era of profound transformation, called either digital (Zisman \& Kenney, 2018) or the second machine age (Bnynjolfsson \& McAfee, 2014), when the very notions of work, fatigue, and well-being are changing in depth, ergonomics/human factors need to be creative in order to meet the new, ever-encountered challenges. Not every contribution in the ten volumes of the Proceedings explicitly faces the problem: the need for creativity to be able to confront the new challenges. However, even the more traditional, classical papers are influenced by the new conditions.

The reader of whichever volume enters an atmosphere where there are not many well-established certainties, but instead an abundance of doubts and open questions: again, the conditions for creativity and innovative solutions.

We hope that, notwithstanding the titles of the volumes that mimic the IEA Technical Committees, some of them created about half a century ago, the XX Triennial IEA Congress Proceedings may bring readers into an atmosphere where doubts are more common than certainties, challenge to answer ever-heard questions is continuously present, and creative solutions can be often encountered.

\section{Acknowledgment}

A heartfelt thanks to Elena Beleffi, in charge of the organization committee. Her technical and scientific contribution to the organization of the conference was crucial to its success. 


\section{References}

Brynjolfsson E., A, McAfee A. (2014) The second machine age. New York: Norton.

Tatcher A., Waterson P., Todd A., and Moray N. (2018) State of science: Ergonomics and global issues. Ergonomics, 61 (2), 197-213.

Zisman J., Kenney M. (2018) The next phase in digital revolution: Intelligent tools, platforms, growth, employment. Communications of ACM, 61 (2), 54-63.

Sebastiano Bagnara Chair of the Scientific Committee, XX IEA Triennial World Congress

Riccardo Tartaglia

Chair XX IEA Triennial World Congress

Sara Albolino

Co-chair XX IEA Triennial World Congress 


\section{Organization}

\section{Organizing Committee}

Riccardo Tartaglia

(Chair IEA 2018)

Sara Albolino (Co-chair IEA 2018)

Giulio Arcangeli

Elena Beleffi

Tommaso Bellandi

Michele Bellani

Giuliano Benelli

Lina Bonapace

Sergio Bovenga

Antonio Chialastri

Vasco Giannotti

Nicola Mucci

Enrico Occhipinti

Simone Pozzi

Stavros Prineas

Francesco Ranzani

Alessandra Rinaldi

Isabella Steffan

Fabio Strambi

Michela Tanzini

Giulio Toccafondi

Antonella Toffetti

Francesca Tosi

Andrea Vannucci

Francesco Venneri
Tuscany Region

Tuscany Region

University of Florence

Tuscany Region

Tuscany Region

Humanfactor $^{\mathrm{x}}$

University of Siena

Macadamian Technologies, Canada

FNOMCeO

Alitalia

Fondazione Sicurezza in Sanità

University of Florence

University of Milan

Deep Blue

ErrorMed

Tuscany Region

University of Florence

Design for all

Etui Advisor for Ergonomics

Tuscany Region

Tuscany Region

CRF, Italy

University of Florence

Agenzia Regionale di Sanità Toscana

Azienda Sanitaria Centro Firenze 


\section{Scientific Committee}

\section{Sebastiano Bagnara \\ (President of IEA2018 \\ Scientific Committee)}

Thomas Alexander

(IEA STPC Chair)

Walter Amado

Massimo Bergamasco

Nancy Black

Guy André Boy

Emilio Cadavid Guzmán

Pascale Carayon

Daniela Colombini

Giovanni Costa

Teresa Cotrim

Marco Depolo

Takeshi Ebara

Pierre Falzon

Daniel Gopher

Paulina Hernandez

Sue Hignett

Erik Hollnagel

Sergio Iavicoli

Chiu-Siang Joe Lin

Waldemar Karwowski

Peter Lachman

Javier Llaneza Álvarez

Francisco Octavio Lopez Millán
University of San Marino, San Marino

Fraunhofer-FKIE, Germany

Asociación de Ergonomía Argentina

(ADEA), Argentina

Scuola Superiore Sant'Anna di Pisa, Italy

Association of Canadian Ergonomics

(ACE), Canada

Human Systems Integration Working

Group (INCOSE), France

Sociedad Colombiana de Ergonomia

(SCE), Colombia

University of Wisconsin-Madison, USA

EPM, Italy

Clinica del Lavoro "L. Devoto," University of Milan, Italy

Associação Portuguesa de Ergonomia

(APERGO), University of Lisbon,

Portugal

University of Bologna, Italy

Japan Ergonomics Society (JES)/Nagoya

City University Graduate School of

Medical Sciences, Japan

CNAM, France

Israel Institute of Technology, Israel

ULAERGO, Chile/Sud America

Loughborough University, Design School, UK

University of Southern Denmark and Chief

Consultant at the Centre for Quality

Improvement, Denmark

INAIL, Italy

Ergonomics Society of Taiwan (EST),

Taiwan

University of Central Florida, USA

CEO ISQUA, UK

Asociación Española de Ergonomia (AEE), Spain

Sociedad de Ergonomistas de México,

Mexico 
Donald Norman

José Orlando Gomes

Oronzo Parlangeli

Janusz Pokorski

Gustavo Adolfo Rosal Lopez

John Rosecrance

Davide Scotti

Stefania Spada

Helmut Strasser

Gyula Szabò

Andrew Thatcher

Andrew Todd

Francesca Tosi

Charles Vincent

Aleksandar Zunjic
University of California, USA

Federal University of Rio de Janeiro, Brazil University of Siena, Italy

Jagiellonian University, Cracovia, Poland Asociación Española de Ergonomia (AEE), Spain

State University of Colorado, USA

SAIPEM, Italy

EurErg, FCA, Italy

University of Siegen, Germany

Hungarian Ergonomics Society (MET), Hungary

University of Witwatersrand, South Africa ERGO Africa, Rhodes University, South Africa

Ergonomics Society of Italy (SIE); University of Florence, Italy University of Oxford, UK

Ergonomics Society of Serbia (ESS), Serbia 


\section{Contents}

\section{Aging}

Impact of Exercise and Ergonomics on the Perception of Fatigue in Workers: A Pilot Study

A. C. H. Pinetti, N. C. H. Mercer, Y. A. Zorzi, F. Poli, E. Nogiri,

A. C. Lima, and M. R. Oliveira

The Use of Technology as a Creative Means of Ergonomics to Support the Realization of Activities in an Aging Population: A Review

Pierre-Yves Therriault, Galaad Lefay, Marie-Michèle Lord, and Alexe Desaulnier

How Age and Pace of Work Affect Movement Variability

During Repetitive Assembly Tasks

Martine A. Gilles, Clarisse Gaudez, Jonathan Savin, Aurélie Remy,

Olivier Remy, and Pascal Wild

Identifying Factors Related to the Estimation of Near-Crash Events of Elderly Drivers.

Misako Yamagishi, Takashi Yonekawa, Makoto Inagami,

Toshihisa Sato, Motoyuki Aakamatsu, and Hirofumi Aoki

The Use of Auditory Presentations in Assisting Older Adults

for Processing Healthcare Information .

Dyi-Yih Michael Lin and Yuan-Ju Hung

Human Factors for Dementia: Evidence-Based Design .

Charlotte Jais, Sue Hignett, and Eef Hogervorst

How Do Municipal Workers Perceive the Changes in Activity

Demands, Based on Age?

C. A. Ribeiro, T. P. Cotrim, V. Reis, M. J. Guerreiro, S. M. Candeias,

A. S. Janicas, and M. Costa 
User-Centered Design Process to Develop Motor Speech Disorder

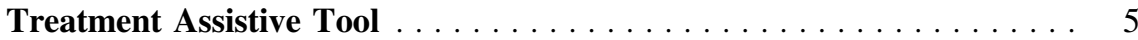

Hsin-Chang Lo, Bo-Kai Peng, and Chia-Chen Li

Force Variability and Musculoskeletal Pain in Blue-Collar Workers . . .

Kristoffer Larsen Norheim, Jakob Hjort Bønløkke, Øyvind Omland,

Afshin Samani, and Pascal Madeleine

Aging and Hand Functions Declining: Assistive Technology Devices

for Assistance in Daily Life Activities Performance . . . . . . . . . . . . . . .

Bianca Marina Giordani and Milton José Cinelli

Falls from Tractors in Older Age: Risky Behaviors in a Group of Swedish and Italian Farmers Over 65

Federica Caffaro, Peter Lundqvist, Margherita Micheletti Cremasco,

Eva Göransson, Stefan Pinzke, Kerstin Nilsson, and Eugenio Cavallo

Virtual Aging - Implementation of Age-Related Human Performance

Factors in Ergonomic Vehicle Design Using the Digital Human

Model RAMSIS

Hans-Joachim Wirsching and Michael Spitzhirn

Aging Ebook: CIIP Silver Book on Aging and Work.

Olga Menoni, Rinaldo Ghersi, and Susanna Cantoni

Early Detection of Fatigue Based on Heart Rate in Sedentary

Computer Work in Young and Old Adults

Ramtin Zargari Marandi, Pascal Madeleine, Nicolas Vuillerme,

Øyvind Omland, and Afshin Samani

Non-pharmacological Interventions for People with Dementia:

Design Recommendations from an Ergonomics Perspective

Gubing Wang, Armagan Albayrak, Johan Molenbroek,

and Tischa van der Cammen

How to Help Older Adults Learn Smartphone Applications?

A Case Study of Instructional Design for Video Training

Fengli Liu and Jia Zhou

Design as a Provocation to Support Discussion About Euthanasia:

The Plug.

Marije De Haas, Gyuchan Thomas Jun, and Sue Hignett

Aging Effects of Inner Character Space and Line Space of Japanese Language

Nana Itoh and Ken Sagawa

Digital Making as an Opportunity for Social Inclusion

Marita Canina and Carmen Bruno 
Evidence Based Data for the Design of Rotary Control Elements

for Fine Motor Adjustment Tasks with Respect to the Elderly User . . . 168

Peter Schmid, Benedikt Janny, and Thomas Maier

Evaluation of Comfortable Using Jerk Method During

Transfer Caring . . . . . . . . . . . . . . . . . . . . . . . . . . . . . . . . . . 178

Ken Ikuhisa, Xiaodan Lu, Tomoko Ota, Hiroyuki Hamada,

Noriyuki Kida, and Akihiko Goto

Towards an Age-Differentiated Assessment of Physical Work Strain . . 189

Matthias Wolf and Christian Ramsauer

Social Medial as Facilitator of Self-value Realization for Elderly . . . . . 206

Dongjuan Xiao and Miaosen Gong

Spatial Optimization of Bedroom Area for Effective Elderly

Patient Handling . . . . . . . . . . . . . . . . . . . . . . . . . . 213

Priyanka Rawal

A Sustainable Working Life for All Ages - The swAge-Model.

Kerstin Nilsson

Gender and Work

Occupational Well-Being of Policewomen in India and China:

Scope of Ergonomic Design Interventions

Shilpi Bora, Debkumar Chakrabarti, and Abhirup Chatterjee

Why Do We Often Forget Gender During Ergonomic Interventions? . . . 245

Karen Messing, Mélanie Lefrançois, and Johanne Saint-Charles

Facets of the Precariousness of Women's Work: Outsourcing

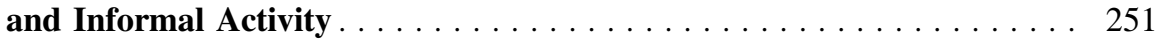

Viviane Herculani Cardillo, Flávia Lima Traldi,

and Sandra F. Bezerra Gemma

Revealing the Hidden Processes Behind Discrimination Against

Part-Time Teachers in France: A Lever for Improving

Their Situation . . . . . . . . . . . . . . . . . . . . . . . . 259

D. Cau-Bareille, C. Teiger, and S. Volkoff

Interventions for Improving Working Environment in Home

Care Work in Sweden - Preliminary Findings from the First Year:

A Gender Perspective . . . . . . . . . . . . . . . . . . . . . . . . . . . . 269

Britt Östlund, Charlotte Holgersson, Rydenfält Christofer,

Inger Arvidsson, Gerd Johansson, and Roger Persson

Analysis of Posture Adopted by Female Kolhapuri Chappal

(Footwear) Manufacturing Workers India .

Urmi Salve and Ganesh Jadhav 
Self-management Process After a Work Accident: A Gender Analysis. . . 287 Liliana Cunha, Cláudia Pereira, Marta Santos, and Marianne Lacomblez

Challenges in Implementing Inclusive Participatory OHS

Management Approaches Sensitive to Gender and Diversity Issues . . . . 294

Valérie Lederer and Jessica Riel

When Being a Woman Represents a Major Risk of Commuting Accidents?

Silvana Salerno and Claudia Giliberti

Telecommuting in Academia - Associations with Staff's Health

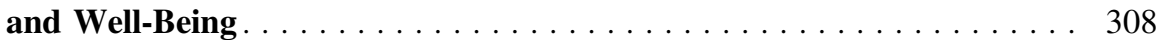

Marina Heiden, Linda Richardsson, Birgitta Wiitavaara, and Eva Boman

Meghalaya Tourism: A Study on Women's Attitudes and Perceptions Towards the Cultural Exposure and Interaction in the Context of Meghalaya Tourism .

Wanrisa Bok Kharkongor, Abhirup Chatterjee, and Debkumar Chakrabarti

A Bio-cooperative Robotic System to Ensure Ergonomic Postures During Upper Limb Rehabilitation in Occupational Contexts

F. Scotto di Luzio, F. Cordella, C. Lauretti, D. Simonetti, S. Sterzi,

F. Draicchio, and L. Zollo

Interrelationship Between Dietary Intake, Bone Mineral Density and Incidence of the Development of Musculoskeletal Disorders in College Students .

Amanpreet Kaur and Ajita Dsingh

Teaching with Gender Perspective Oriented to the Training of Women Students of Interactive Design and Interactive Technologies . . . . . . . . 344 Mercado Colin Lucila and Rodea Chávez Alejandro

Gendered Indicators in OHS: A Number to Convince

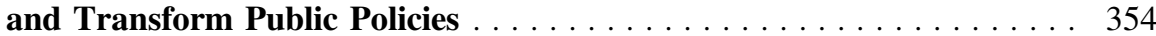
Florence Chappert

A Brand-New Risk in Japan?-Risks of Industrial Accidents in the Age of Diversity Management and Their Countermeasures . . . . 363 Hongson Shin

Theoretical Bases of New Work Simulator-Based Aptitude Assessment in Vocational Guidance of Students with Disability or Special Educational Needs

Erika Jókai

Ergonomic Risk Factors in Women Workers Involved in Handicraft Industry of Patiala District 


\section{Anthropometry}

"La Fabbrica si Misura": An Anthropometric Study of Workers at FCA Italian Plants . . . . . . . . . . . . . . . . . . . . . . . . . 389

Stefania Spada, Raffaele Castellone, and Maria Pia Cavatorta

Anthropometric Data for Biomechanical Hand Model

Kyung-Sun Lee, Myung-Chul Jung, Seung-Min Mo, and Seung Nam Min

The Definition and Generation of Body Measurements

Youngsuk Lee

Anthropometric Dimension of Agricultural Workers in North

Eastern Thailand

Ekarat Sombatsawat, Mark Gregory Robson, and Wattasit Siriwong

Anthropometric Survey of Chinese Adult Population

Chayi Zhao, Linghua Ran, Taijie Liu, and Aixian Li

Use of Anthropometry and Fit Databases to Improve

the Bottom-Line

Kathleen M. Robinette and Daisy Veitch

Importance of Human Anthropometry in the Interior Development of Autonomous Vehicles

Sibashis Parida, Samuel Brock, Sylvester Abanteriba, and Mattias Franz

Anthropometric Implications of the Global Obesity Epidemic 464

Bruce Bradtmiller, Neal Wiggermann, and Monica L. H. Jones

SOOMA - Software for Acquisition and Storage of Anthropometric

Data Automatically Extracted from 3D Digital Human Models

Flávia Cristine Hofstetter Pastura, Tales Fernandes Costa,

Gabriel de Aguiar Mendonça, and Maria Cristina Palmer Lima Zamberlan

Design for Plus Size People

J. F. M. Molenbroek, R. de Bruin, and T. Albin

Estimating Anthropometric Measurements of Algerian Students with Microsoft Kinect.

Mohamed Mokdad, Ibrahim Mokdad, Mebarki Bouhafs, and Bouabdallah Lahcene

Grip and Pinch Strength of the Population of the Northwest of Mexico

Enrique de la Vega-Bustillos, Francisco Lopez-Millan,

Gerardo Mesa-Partida, and Oscar Arellano-Tanori 
Hand Dimensions and Grip Strength: A Comparison of Manual

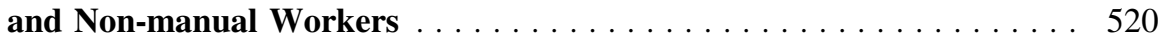

Mahnaz Saremi and Sajjad Rostamzadeh

Estimation to Use the Stick Figure of Kinect ${ }^{\circledR}$ Version 2

for Digital Anthropometry . . . . . . . . . . . . . . . . . . . . . 530

Sabine Wenzel, Juliana Buchwald, and Hartmut Witte

Assessment of Dimensional Needs for Designing Spaces

for Wheelchair Users . . . . . . . . . . . . . . . . . . . . . . . . . . . . . 544

Adrián Leal-Pérez, Libertad Rizo-Corona, John Rey-Galindo,

Carlos Aceves-González, and Elvia González-Muñoz

Latin American Schoolchildren Anthropometry: Study

of the Anthropometric Differences of the Rural and Urban Zones

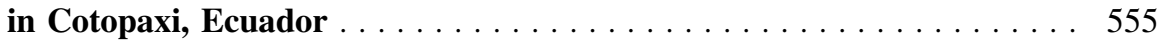

T. Wendy L. Velasco and C. Cristina Camacho

How to Assess Sitting (Dis)comfort? - An Analysis of Current

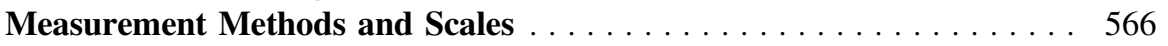

Annika Ulherr and Klaus Bengler

Evaluation of an Adaptive Assistance System to Optimize Physical

Stress in the Assembly . . . . . . . . . . . . . . . . . . . 576

Katharina Rönick, Thilo Kremer, and Jurij Wakula

Anthropometry for Ergonomic Design of Workstations: The Influence of Age and Geographical Area on Workers Variability . . . . . . . . . . . 585

M. Micheletti Cremasco, A. Giustetto, R. Castellone, M. P. Cavatorta, and S. Spada

Modeling People Wearing Body Armor and Protective Equipment: Applications to Vehicle Design .

Matthew P. Reed, Monica L. H. Jones, and Byoung-keon Daniel Park

Anthropometric Characteristics of Chilean University Students and Their Relation with the Dimensions of the Furniture of the Lecture Rooms .

J. Freire, E. Apud, F. Meyer, J. Espinoza, E. Oñate, and F. Maureira

Anthropometric Factors in Seat Comfort Evaluation: Identification and Quantification of Body Dimensions Affecting Seating Comfort Benjamin Heckler, Manuel Wohlpart, and Klaus Bengler

3D Body Modelling and Applications .

S. Alemany, A. Ballester, E. Parrilla, A. Pierola, J. Uriel, B. Nacher,

A. Remon, A. Ruescas, J. V. Durá, P. Piqueras, and C. Solves 
Ergonomics for Children and Educational Environments

Differences in Visual Attention Performance Between Action

Game Playing and Non-playing Children

Min-Sheng Chen, Tien-Sheng Chiu, and Wei-Ru Chen

Relationship Between Educational Furniture Design

and Cognitive Error .

Ali Jafari, Shirazeh Arghami, Koorosh Kamali, and Saeedeh Zenozian

The Differences Between Bowing as Among Adult Members

of Society in Japan and the Bowing of Japanese Students

Kohei Okado, Hiroyuki Hamada, Noriyuki Kida, Tamotsu Matsuda,

Rie Ohashi, Kazuki Kitamura, Andy Smith, David Todisco,

Luke Jackson, and Tatsuya Ogimoto

Using Natural Gesture Interactions Leads to Higher Usability

and Presence in a Computer Lesson

Shannon K. T. Bailey, Cheryl I. Johnson, and Valerie K. Sims

Ergonomics Teaching Concept at Technical Universities

on the Basis of Warsaw University of Technology

Ewa Górska and Aneta Kossobudzka-Górska

Children's Creativity at School: Learning to Produce

Multimedia Stories .

Laura Anastasio Forcisi and Françoise Decortis

"Ergonomics on the Ground": A Case Study of Service Learning

in Ergonomics Education .

Jonathan Davy, Kim Weaver, Andrew Todd, and Sharli Paphitis

A Quantitative Content Analysis of L1 and L2 English Writings

Using a Text Mining Approach

Ikuyo Kaneko

Effect of Redesigning School Furniture Based on Students'

Anthropometry in North-West Nigeria .

Ademola James Adeyemi, Paul Ojile, Muyideen Abdulkadir, and Olusegun Isa Lasisi

Digital Discrimination: An Ergonomic Approach to Emotional

Education for the Prevention of Cyberbullying

Margherita Bracci, Alison Margaret Duguid, Enrica Marchigiani,

Paola Palmitesta, and Oronzo Parlangeli

Playful Learning for Kids with Special Educational Needs

Elisabetta Cianfanelli, Pierluigi Crescenzi, Gabriele Goretti, and Benedetta Terenzi 
Influence of Varying Backpack Loading and Velotypes on the Spatiotemporal Parameters of Gait and Energy Cost of Ambulation Among Primary School Children in Nigeria .

Echezona Nelson Dominic Ekechukwu, Callistus Chukwuwendu Okigbo, Adaobi Justina Okemuo, and Chioma N. Ikele

Text Neck, More Technology, Less Health? 758

Sandra Zamira Genez Tarrifa and Ricardo De la Hoz Lara

Incidence of the Psychosocial Risk at Work: A Case Study of Technical Teachers at City of Morón. 768 Concepción Nicolás Hernán

Maximum Acceptable Weight of Lift in Adolescence Aged 15 to Less Than 18 Years Old

Naris Charoenporn, Amata Outama, Teeraphan Kaewdok, Poramate Earde, and Patchree Kooncumchoo

Interdisciplinary Adaptation and Extension of the User Experience Questionnaire for Videos in Learning Environments . . . . . . . . . . . . . 789 Aline Lohse, Alexander Aust, Janina Röder, and Angelika C. Bullinger

Way-Finding and Communication Design as Strategic Systems to Improve the Well-Being of Children in Paediatric Hospitals 799

Laura Giraldi, Marta Maini, and Donatella Meloni

Racial Effect on the Recommended Safe Weight for Backpack

Users Among Schoolchildren

Ademola James Adeyemi, Jafri Mohd Rohani, and Mat Rebi AbdulRani

Human Factors/Ergonomics Education and Certification:

The Canadian Experience

Nancy Black and Judy Village

Musculoskeletal Disorders in Indian School Children Due

to Carrying Heavy Back Packs

Deepak Sharan

Musculoskeletal Disorders in 115 Students Due to Overuse of Electronic Devices: Risk Factors and Clinical Features 828

Deepak Sharan

Author Index. 


\title{
Way-Finding and Communication Design as Strategic Systems to Improve the Well-Being of Children in Paediatric Hospitals
}

\author{
Laura Giraldi $^{1(\bowtie)}$, Marta Maini ${ }^{1(\bowtie)}$, and Donatella Meloni ${ }^{2(\bowtie)}$ \\ ${ }^{1}$ University of Florence, Florence, Italy \\ Laura.giraldi@unifi.it, marta.maini@hotmail.it \\ 2 St. Peter Pediatric University Hospital, AOU Sassari, Sassari, Italy \\ San. Pietro.donatella.meloni@aousassari.it
}

\begin{abstract}
In recent years there has been a growing need to design way-finding systems and communication more effectively, as we realize the great importance they have in everyday people's life, becoming necessary and operative guidelines tools for improving the quality of life. Sometimes these tools are used as simple signposting or mere decorations designed to embellish a specific space, as happens in place dedicated to children. Instead they are very important and strategic instruments able to improve the liveability and usability of specific environment by different kind of users. Among these ones, the children are very particular, because they feel, think and behave in a very different way beside the adults.

Generally, the hospital environment causes a high level of stress in children. Indeed, because of their young ages, they have a very limited experience and therefore they do not have the psychological and emotional state to deal with kind of stressful environment.

Way-finding systems and communication design products improving the user experience, are able not only to orient children inside unknown spaces, but also to make "familiar" a place never seen before, making the child feels at ease, avoiding or reducing the stress that this place can bring to the user.
\end{abstract}

Keywords: Way-finding $\cdot$ Communication $\cdot$ Children $\cdot$ Well-being Pediatric hospital

\section{Introduction: Context of Reference}

\subsection{Wayfinding Systems}

In our days people spend a significant part of their life outside home by living outdoor or indoor public spaces to live experiences or socialize with the others. During this kind of experience people need to "find their way". Sometimes they become disoriented in the event of there being difficulties in reaching their destination or in case of losing their sense of orientation during the journey. In such situations, way-finding systems help to keep guidance and give people the means to feel comfortable in new environments. In case of young people the problem is even more complicated because they have more difficulty in recognizing unknown or non-familiar places. Today there are 
just few examples of way-finding systems and communication design products, which are especially designed according to children needs and their psycho-physical and emotional characteristics.

Generally, way-finding systems dedicated to children are not easy to be found in modern cities' indoor or outdoor spaces. This is probably due to the fact that young people are always associate with an adult or live experience under the supervision of a helper. So, the guidance is demanded to the adults (parents, teachers, etc.) going along them. When children grow up and reach the age of over six/seven years, sometimes they succeed in following way-finding systems designed for adults, as, for examples in the underground big cities, such as an example Milan in Italy, because, in this case, the signs are clearly visible and recognizable, well organized, placed also on the ground (easy to see and follow). Moreover, each route is identified by graphic elements of a specific color. In spaces and along routes where way-finding systems are not installed, people follow undersigned signs they find in the environment. Indeed, this is the case, as instance, of urban scenarios, where they use for orienting shop windows, mail boxes, bus shelter, advertising signs. A similar case apply in indoor public spaces, where those elements are represented by lifts, stairs, corner, lights, signposting and so on. All of these elements realize spontaneous way-finding systems that often are not sufficient for navigation.

Unlike external environments, in interiors spaces dedicated to childhood such as schools, play-rooms and pediatric hospitals, actually it is possible to find few examples of way-finding systems. All of them are characterized by a vast wealth of colors and graphic elements, like stylized animals remembering tales and cartoons, which can be easily to recognized by children. "In developing the wayfinding strategy and designing the sign system, the designer will have to create a family of sign types that not only addresses primary information and wayfinding needs but also recognizes secondary issues and audiences with an appropriate information hierarchy and sign-messaging protocols" [9].

Furthermore "symbol design is equally important to wayfinding. Symbols provide a shortcut way for large groups of people who may not share a common language to Communicate" [9].

Generally, wayfinding systems are represented by different kind of "signs" inside connection areas, especially in the cities characterized by streets, path walks, squares, parks, gardens and playground. In the contexts, streets represent the connection areas used by people to go from one place to another, while the other urban spaces are also used for socialization and free time. In public interior environments the wayfinding systems have the same functions. The first one is practical or denotative [7] and consists in orienting people inside the space. The second "function", defined connotative [7] is related to the emotional sphere, it involves the senses of the users remembering familiar elements and actions and suggesting behaviors or relation among users.

As a consequence, we can state with a certain level of confidence that a way-finding design for little users could help them to feel comfortable even if they are in an unfamiliar space as a hospital, which is generally perceived as hostile. 
If we consider children as main user of a collective interior space we can say that it is not easy to find interesting examples of places with way-finding systems designed at "children's size".

Generally speaking, the hospital environment causes a high level of stress in children. Indeed, because of their young ages, they have a very limited experience of life and therefore they do not have the psychological and emotional state to deal with kind of stressful environment. For this reason wayfinding systems and communication design products able to improve their experience as users, are able not only to orient children inside unknown spaces, but also to make "familiar" a place never seen before, making the child feels at ease, avoiding or reducing the stress that this place can bring to the user.

\subsection{Pediatric Hospital}

The hospital is a building which welcomes patients and dispenses a wide range of medical care services. To these, the medical staff and everybody who need to go in it, both patients and their relative, have be added. The pediatric hospital, from an organizational point of view, is mainly divided in three classes: hospitalization, diagnostictherapeutic and general services.

Furthermore, there are also the spaces which host the machineries and those dedicated to didactics. Differently from a normal hospital, the pediatric have some peculiarities, first regarding the subdivision of hospitalization in relation to the patients' age. This is necessary due to the furniture, which is adapted respect to the specific measures of the children, accordingly to each age. In general, in the services class are included playing spaces, green spaces and those dedicated to didactics. All of those have a specific aim: entertain the children, distracting them from their illnesses, but also amuse the medical staff. The life in the hospital is perceived as extraneous by the routine and habits of everyday life. These are replaced by rules and strict rhythms of medical care. During the hospitalization experience can also incur relational problems, caused by a depersonalized environment.

There are indeed several studies that proved the importance of creative stimulation as a valid method to fight depression brought by disorientation and identity loss. As previously said, the hospital users are not only the patients, but also all the relatives which help them in carrying out the hospitalization or visit them. In every case, often, all the persons that are in the hospital, as main or secondary users, are requested to wait for. Consequently making enjoyable and interesting the transit and waiting places has been became of fundamental importance.

\subsection{Children and Parents' Stress in Pediatric Hospital}

Stress is a concept scientifically defined and an evincible phenomenon. In 1998, Evans and Mitchell McCoy, described the way a built environment may influence the health of persons and found which architectonic elements may lead relevant stress in the users. The characteristics of the building' spaces that may lead stress are basically four: stimulation, coherence, affordance and control. 
In the hospitalization matter, the stress phenomenon assumes a relevance, because this may negatively influence the clinical outcome of the patient.

Subsequently to further studies and researches, two ways in which stress impact on patients' health were identified:

- Negatively impacting directly on health patients (physiological parameters: blood pressure, state of anxiety, depression, etc.)

- Negatively impacting on medical staff performances. In the hospital, in fact, may be found two types of stress: environmental and occupational.

According to Ulrich, Devlin, Arneill and Del Nord, the elements of the building that may represent possible stress vehicle for users are the following:

- The image itself of the hospital.

- Sensorial feelings.

- Difficulties, impossibility in control and manipulate the environment.

- Orientation difficulties.

- Physical discomfort.

- Viral risk.

The Orientation Difficulties. The orientation difficulties are typical of the hospital.

It is a common belief, in fact, that the hospital is somehow similar to a labyrinth, due to its endless corridors, often identical. Wayfinding problems impact not only on patients, but everybody experiences the place, i.e. the relatives and the medical staff, forced to interrupt their mansions for helping the users to find their way. Users are scared to get lost, to not find anymore the way to come back and, for that reason, they not completely enjoy whole the services offered by the structure. These problematic in the long run become, not only a relevant source of stress, but also a cost for the health company.

Differently from other hospitals, patients of pediatric hospital experience a continuous evolution and this make harder identifying precisely all possible source of stress. For this reason, is necessary looking the space with the perspective of the children, because what may appear beautiful or enjoyable for an adult, may look boring or even anxiogenic for children.

The child has a limited emotional experience to face the challenge resulting from hospitalization and, for this reason, he/she may be more vulnerable respect to different sources of stress.

\subsection{Pediatrician's Point of View}

The design and architecture of spaces dedicated to pediatric ward may have a relevant psychological impact on children and their family.

Design and architecture may improve the permanence of patients and their relatives in the hospital and, at the same time, they may have a positive impact on the activities of whole the medical staff. The latter face a stress often higher than other due to emotional implication respect to their young patients.

The child should first enter in a comfortable, lovely, relaxing and colorful place which evokes protection and peacefulness. 
A child-friendly environment that arouses family like feelings, esthetically tidy and enjoyable, contributes to the rehabilitation and wellness, which also may result in a shorter permanence of the patient. All of that would lead benefit, not only to the children, but also to whole the relatives that face up the hospitalization with them.

\section{The Aim of the Research}

The aim of the present research is to propose an innovative approach in the designing for kids discipline by individuating a series of good practices for the strategic design of communication and way-finding systems to be applied in indoor spaces dedicated to children and, in particular, in several areas within pediatric hospitals. In order to improve the well-being of children and make them feel comfortable in indoor public spaces and, in particular, in the pediatric hospital interiors, it is necessary to render those spaces more friendly.

These good practices have to guide designers to design interior way-finding systems able to orient, inform, interact, entertain include all kind of children, at different ages, using one universal language of their collective imaginary. In order to improve this new design culture, the purpose of this work is to recommend a methodological referring system to be easy applied in different indoor places dedicated to children.

The suggested good practices are designed taking into account the peculiarities (skills, abilities, behaviors) of children at the different ages groups in accordance to the theory above mentioned. In other words, the purpose of this work is to propose a referring methodological system to design way-finding systems in indoor collective spaces able to communicate with all kind of children according to two different modes of interaction.

The first communication mode is designed to orientate children guiding them along interiors without losing their way and informing them about surrounding areas and services. It is based on simplified orientation and secure informative messages. These kinds of systems are usually founded on children behavior so that children use their previous experiences to find their way.

The second one stimulates the emotional sphere of children and allows them to live pleasant experience in an unknown place. It concerns the connotative meaning of signs able to entertain and reassure, suggesting familiar routine and known practices belonging to their imaginary. This kind of communication is based on the knowing of children' imaginary belonging to the experiences of their life.

Summarizing the final research's aim is to find open rules and good practices for the design of way-finding systems able to orient, to reduce stress and feel at ease a large number of children in unknown indoor collective spaces.

These goals also allow communicating with children as main users and indirectly with parents and health staff according to different levels of interactions. 


\section{Methods of Research}

\section{1 “Children Centered-Design": Multidisciplinary Approach}

Way-finding systems have the function to advice or remind people about the surroundings, presenting the information at strategic points to orient and inform them. Children have a different ability of orientation in comparison with the adults and for this reason it is necessary to study their skills and behaviors at the different ages before start designing for them. Consequently, it is necessary to define a design method for way-finding systems based on and strongly taking into account the natural skills, behaviors and inclinations of children. In this way it is possible to design a system really able to guide and entertain children in a pleasant way using strategic solutions.

The methodological approach to design communication and way-finding systems in collective interiors and in particular in pediatric hospitals refers to the human centered design rules in order to inform the little users about surroundings and giving them points of view and references for finding their way in autonomy as in a familiar place.

The present work uses a multi-disciplinary and holistic approach involving different disciplines essential to study the children as main users. As a matter of fact, from the birth to adult age, young people have a continuous development of physical and psychical abilities, which are necessary to know in order to design according to children centered design approach.

The involved disciplines are mainly pedagogy, cognitive psychology and pediatrics. The contributions of each discipline represent the indispensable basic knowledge necessary to summarize all the features in the final design proposal.

Starting from pedagogy, the research refers to the educational theories of Montessori, [25] and of Loris Malaguzzi [22] whose educational theory is known as Reggio Children approach. These two Italian pedagogical theories are ones of the most followed in the world. Among their various indications, they identify the environment where children live as an essential support for the growth and development of them, to enhance their potential, resources and many intelligences. [8] Consequently, it is very important that the environments where children live - from a domestic interior to a hospital - are designed taking into account the pedagogical theories mentioned above. Consequently, the designer can use all the information to design way-finding systems for pleasant and inclusive experiences. The children's indoor environment characterized by ad hoc "elements", colors and graphics play a fundamental role, determining a scenario such as to be perceived by the child as friendly, pleasant, safe and familiar, do not allowing them, to lose their way. The scholars also identified three age groups of reference, $0-3,3-6$ and 7-11 years old. These groups are indicative of the steps of growth and related skills and abilities, as also explained in the cognitive psychology theories by Piaget [29] in the Sixties. Moreover, Piaget highlighted the importance of playing for children. It is sure enough that when children play they show their needs to communicate their own emotions. Certainly, the designers will have to take into account this information when designing for kids. Environments and products able to induce behaviors focus on the emotional aspects that, as Norman says, [27] they are the engines of psycho-physical development and learning. 
The technique of playing represents a solution for the designer able to realize this contact with the little user. When children play they underline their needs to communicate and socialize and, at the same time, show their inner emotional world. In designing, it is modus operandi the involvement of the main and secondary users in co-working activities at the early stages of job definition.

The strategy of involving small users in co-working is necessary for highlighting the relations between the type of actions and the emotions happening in an experience inside unknown spaces.

In general, this is an important activity because it is able to make designers think in an innovative way. The co-working approach has been experimented as described below during the development of the present work.

\section{Applied Method. Use Case: Pediatric Hospital in Sassari Italy}

The research described in this paper investigated the following aspects, by relating them with the specific scenarios of the Pediatric Hospital at Sassari:

- Study of the literature: perception psychology, pedagogy, pediatrics, children skills and behavior at different ages, way-finding systems, children design, communication design, human factor design.

- Direct observation of children in connective and waiting areas of pediatric hospitals (as guests and as patient) - as explained in the use case below.

- Interviews to medical, health staff and parents for detecting problems of orientation both for them and for kids in collective areas of pediatric hospital.

- Co-working activity with children aged 7 to 12 years.

- Collection and comparison of results.

This practical activity with the children was based on the detection of their mood and needs when they are in the hospitals as guests or as patient.

The purpose of this co-working activity is also to know if and how children feel at ease and if they have difficult to orientate in public collective areas in hospitals. Moreover, the experimentation aim to identify possible real solutions interpreting children suggestions.

The results have the function to verify possible solutions and also to contribute to specify good practices to design a way-finding system able to guide little users, orienting and informing them with the use of the colors and familiar elements according to their own language and imaginary in a pediatric hospital.

Equally the method highlights the elements that are critical and do not let children feel at ease and live a pleasant experience. 


\subsection{Use Case}

The experiment was set-up in Sassari (Italy), a small town in the north of Sardinia, at the St. Peter Pediatric University Hospital, which is the second most important pediatric clinic in the island and that, during summer, it becomes the point of reference also for tourists of the all northern coast.

The research has implemented three main actions which allowed to understand better children behaviors: direct observation, interviews and co-working initiatives together with children.

First Activity Direct Observation. It started considering the waiting areas in the ward, in emergency care units and the connection spaces among different clinics. The experimentation activities have involved children aged from about three to twelve years old visiting the hospital. Children were belonging to different nationalities. The observation showed how all the children were interacting with hospital environment and interior settings and how they were moving in the surrounding environment with and without their parents.

The method's application points out, for the most, the difficulties of all the children to be oriented and feel comfortable. We discovered that the main activity that children of all ages have in common, is playing. Besides, the observation highlighted how children, inside these spaces, used to play mainly together with well known and familiar elements, even if they were not designed specifically for playing. The observation also underlined that children were attracted mainly by multimedia and interactive elements present in the areas, even if they are not addressed to them.

Moreover, we observed that the more common behaviors of kids were inspired by different kind of space elements such those, for instance, floor's tiles inspiring the game "the floor is lava" or grouts spacing of flooring which inspire balances games.

Second Activity Interviews. In a second moment, frontal and questionnaire interviews were conducted both by the medical, paramedical and technical staff, and by visitors and patients' relatives to the structure. The questions asked to visitors required an evaluation of the interior hospital's and way-finding system. The results of the interviews showed that visitors found the internal signage very poor and causing a lot of difficulties in orientation within the hospital. The interviews' answers underlined that, very often, visitors were used to ask the staff the best path to reach their destination. Moreover the questions asked to the hospital's staff required an evaluation of the interior hospital's signage and wayfinding system.

The results of the interviews con-firmed that very often the hospital's staff is distracted by visitors asking information, which is usually cause of stress. This habit suggests the necessity of improving the communication and wayfinding system.

Third Activity Co-working with Children. The third action of co-working with children was carried out thanks to the collaboration with six schools in the city of Sassari. The workshops involved children aged 7 to 12 years. This activity, referring to the studies carried out by Filippazzi on the need for a group "vaccination" [9] to be implemented in schools to ensure that children could live better the experience inside 
the hospital, allowed to make the hospital known outside the hospital building, involving children and making this place more familiar to them.

During laboratories carried out in co-working, children, followed by pediatricians, pedagogues and designers, drew a series of characters that they would like to see inside a hospital, and that could "make them feel better".

The co-working allowed the researchers to highlight the thoughts, the emotions and the imaginary of the children related to the hospital environment.

\section{Results of the Research}

\subsection{Good Practices}

The present work states that collective and connective spaces, in pediatric hospitals, have to be characterized by specific way-finding systems and signs/elements designed ad hoc. These ones have to facilitate orientation and relations, to stimulate interaction and imagination and encouraging the socialization and the playing for well-being of children.

As a result, the research proposes a series of good practices, which are easily applicable to different kind of pediatric hospital interiors, both for new hospitals and for existing ones. The following steps describe the actions useful to design way-finding systems.

What is necessary to individuate:

- Collective areas (i.e., waiting room, bathroom, restaurant, play room, library, etc.) that needed to be reached by children.

- Corridors and connective spaces that are necessary to walk to go from one area to another.

- Each existing element (i.e. doors, baseboard, windows, switchboard, signage, etc.) in the above spaces, which could be necessary to re-design or taking into account for the way-finding design. This point is valid only for existing hospitals.

What is necessary to define:

- The optimized ways for easy orientation.

- All the elements (material and/or graphic) specifying the colors to be used, the shapes and the illustration according to the imaginary of children, able to improve children's perception of indoor spaces. All of these elements are designed as a "family of sign types" [10] placed in a recurrent mode along the way, according to the rules previously defined. Following this indication, it is suggested to design a coordinated image manual describing exactly the rules of the system.

What is necessary to determinate. The strategic communicative functions of each "element" used to design the way-finding systems, in particular between:

- Basic function: able to orient and to inform about the surroundings, realized by visual communication on the floor and on the walls positioned at a height not exceeding one meter and half (related to children height to be easy visible by them). 
- "Emotional" function, with connotative meaning: able to reassure, engaging the senses, and entertain, realized through familiar elements and the practice of playing, remembering pleasant situations and actions of their daily life.

The connotative functions include many messages differently understood by children in relation to their ages, their cultural baggage and their knowledge. Generally, they refer to "elements" of children's imaginary. They could be iconic inspired by natural elements as animals, flowers, etc. or coming from tales, games, video games, cartoons, etc.

\subsection{Results}

Another very important practice that characterized children life is the playing as underline also Piaget [29].

It is quite sure that when kids play they show their own emotions together with their desire of communicate.

As a result of the observation of children at hospital and of the co-working activity (as described above) it is important to underline the importance on playing both in traditional way, - as for example symbolic or vertigo games - than in virtual one, as video games and app used by children, which are digital natives, with satisfaction and easiness. All the communicative elements of the way-finding system should stay on the following features:

- To be ludic: graphic or material elements suggesting or remembering familiar games-usually acted at home, at school or at playground. As an alternative, interactive elements offering familiar tools like video games to be used only in common waiting areas to entertain.

- To be defined by specific colors and simple shapes: easy to identify and recognize inside an interior, also encouraging creativity in differently aged children.

- To be sensory interactive: stimulating curiosity and pleasant emotions, and at the same time, feeling children well and at ease.

\section{Conclusions}

In this paper we have identified a set of design principles and good practices to define the hospital spaces through wayfinding systems design according children needs with the final aim to improve children hospital experience. The result of the present work highlights that collective spaces for children, as pediatric hospitals, need new wayfinding and communication systems designed ad hoc in order to render the interiors familiar for the little users feeling them at ease. Besides, the research claims that familiar elements (both material and graphic) are responsible of pleasant experience influencing the well-being of children and consequently facilitating the disappearance of stress and a speedy recovery.

Basically, children need emotional way-finding systems designed using natural stylized elements to live experiences in security and in freedom. 
We hope to share the result of the present work in order to apply and to develop the proposed open rules for designing more and more hospital's interiors children-centered in the next future.

\section{Appendix}

Author Laura Giraldi has coordinated the overall writing process of the paper and has written the following sections: 1.1 "Wayfindind Systems", 2 "The Aim of the Research", 3 "Methods of Research", 4 “Applied Method. Use Case: Pediatric Hospital in Sassary (Italy)", 5 "Results of the Research", 6 "Conclusions".

Author Marta Maini has written the following sections: 1.2 "Pediatric Hospital", 1.3 "Children and Parents' Stress in Pediatric Hospital", 4.1 "Use Case".

Author Donatella Meloni has written the following sections: 1.4 "Pediatrician's Point of View".

\section{References}

1. Baraldi C, Maggioni G (2000) Una città con i bambini. Donzelli, Roma

2. Callois R (2000) I giochi e gli uomini. Bompiani

3. Campos Andrade C, Sloan Devlin A (2015) Stress reduction in the hospital room: applying Ulrich's theory of supportive design. J Environ Psychol 41:125e134

4. Carpuso M, Trappa MA (2005) La casa delle punture. La paura dell'ospedale nell'immaginario del bambino. Ma. Gi

5. Carpuso M (2001) Gioco e studio in ospedale. Creare e gestire un servizio ludico-educativo in un reparto pediatrico. Erickson, Trento

6. Del Nord R (2006) Lo stress ambientale nel progetto dell'ospedale pediatrico. Environmental stress prevention in children's hospital design: indirizzi tecnici e suggestioni architettoniche. Motta architettura, Milano

7. Eco U (1975) Trattato di semiotica generale. Bompiani, Milano

8. Edwards C, Gandini L, Forman G (a cura di) (2014) I cento linguaggi dei bambini. L'approccio di Reggio Emilia all'educazione dell'infanzia. Edizioni Junior

9. Filippazzi G (2004) Un ospedale a misura di bambino. Esperienze e proposte. FrancoAngeli, Milano

10. Gibson D (2009) The wayfindg handbook. Princeton Press, New York

11. Giraldi L (2014) Kidesign. Altralinea edizioni, Firenze

12. Giraldi L (2018) Il design pensato ad hoc per i bambini. In: Luisa C, Raffaella F, Benedetta SM (a cura di) Design su Misura. Atti dell'Assemblea annuale della Società Italiana di Design. Società Italiana di Design, Venezia

13. Giraldi L, Benelli E, Vita R, Patti I, Filieri J, Filippi F (2017) Designing for the next generation. Children urban design as a strategic method to improve the future in the cities. Des J 20:sup1

14. Golledge RG, Jacobson RD, Kitchin R, Blades M (2000) Cognitive maps, spatial abilities, and human wayfinding. Geograph Rev Japan 73(Ser. B), No. 2:93-104

15. Harris PL (1991) Il bambino e le emozioni. Raffaello Cortina Editore, Milano 
16. Hillier B, Hanson J (1988) The social logic of space. Cambridge University Press, Cambridge

17. Hughes FP (1999) Children, play, and development, 3rd edn. Allyn and Bacon, Needham Heights

18. Jansen-Osmann P, Wiedenbauer G (2004) The representation of landmarks and routes in children and adults: a study in a virtual environment. J Environ Psychol 24:347-357

19. Kanizsa S, Dosso B (2006) La paura del lupo cattivo. Quando un bambino è in ospedale. Maltelmi, Roma

20. Lewis D, Miller C (1999) Wayfinding: effective wayfinding and signing systems guidance for healthcare facilities. Stationery Office, London

21. Lingwood J, Blades M, Farran EK, Courbois Y, Matthews D (2015) The development of wayfinding abilities in children: learning routes with and without landmarks. J Environ Psychol 41:74e80

22. Cagliari P, Castagnetti M, Giudici C, Rinaldi C, Vecchi V, Moss P (2016) Loris malaguzzi and the schools of reggio emilia. A selection of his writings and speeches. Routledge, UK, pp 1945-1993. (McGraw-Hill)

23. Monsa AK (2000) We the Peoples. United Nations, New York

24. Montessori M (1950) La scoperta del bambino. Garzanti, Milano

25. Montessori M (1949) Dall'infanzia all'adolescenza. Garzanti, Milano

26. Montessori M (1970) Educazione per un mondo nuovo. Garzanti, Milano

27. Norman DA (2004) Emotional design. Perché amiamo (o odiamo) gli oggetti della vita quotidiana. Apogeo, Milano

28. Petrillo M, Sanger S (1980) Emotional care of hospitalized children: an environmental approach, 2nd edn. JB Lippincott, Philadelphia

29. Piaget J (1967) Lo sviluppo mentale del bambino e altri studi di psicologia. Einaudi, Torino

30. Piaget J (1970) La psicologia del bambino. Einaudi, Torino

31. Vechakul J, Patel Shrimali B, Sandhu JS (2015) Human-centered design as an approach for place-based innovation in public health: a case study from Oakland, California. Matern Child Health J 19:2552-2559 